\title{
Postural change of intraocular and blood pressures in ocular hypertension and low tension glaucoma
}

\author{
Shigeki Yamabayashi, Romulo N Aguilar, Motohiro Hosoda, Shigeo Tsukahara
}

\begin{abstract}
The effect of body position on the intraocular and blood pressures of normal volunteers and of patients with ocular hypertension and low tension glaucoma was studied. Changing from the sitting to the supine position increased the intraocular pressure by an average of 4.4 (SD $2 \cdot 0$ ) $\mathrm{mm} \mathrm{Hg}$ in the control group, 4.0 (SD 2.0) $\mathrm{mm} \mathrm{Hg}$ in the ocular hypertension group, and 4.1 (SD $1.8 \mathrm{~mm} \mathrm{Hg}$ ) in the low-tension glaucoma group. After 30 minutes in the supine position the intraocular pressure in normal volunteers and patients with low tension glaucoma remained stable. In contrast patients with ocular hypertension showed a further significant increase in intraocular pressure of 1.6 (SD 2.8$) \mathrm{mm} \mathrm{Hg}(p=0.004)$. This was accompanied by an equally significant decrease in blood pressure $(\mathbf{p}<\mathbf{0 . 0 0 1})$. We believe that these are manifestations of different mechanism of intraocular pressure regulation between these groups.
\end{abstract}

It is well recognised that a change in body position alters intraocular pressure. Several authors have reported an average rise of $2-3 \mathrm{~mm}$ $\mathrm{Hg}$ in intraocular pressure when body position is changed from sitting to supine. ${ }^{1-4}$ Some even report changes as high as $6 \mathrm{~mm} \mathrm{Hg.}{ }^{56}$

In a previous report Williams, Peart, and Letley $^{7}$ studied postural changes of intraocular pressure in relation to blood pressure. They studied normal and systemic hypertensive persons and found no correlation between individual changes of systemic pressure and the magnitude of the rise in intraocular pressure in association with the change from sitting to supine. However, they discovered that patients with systemic hypertension continued to show rises in intraocular pressure even after 15 minutes in the supine position, in contrast to the normal control group in whom the intraocular pressure remained stable.

The relationship of blood pressure to blood flow is well established, and it is believed that abnormalities in autoregulation of blood flow at the optic nerve head may have an important role in pressure-induced axonal loss. ${ }^{8}$

We considered therefore it would be interesting to investigate the relationship between blood pressure and intraocular pressure in two clinical entities which probably represent the extremes of the glaucoma spectrum - ocular hypertension and low tension glaucoma. In the former there is an increased intraocular pressure without the resultant pathological changes of open angle glaucoma. In the latter changes associated with glaucoma are present despite apparently normal intraocular pressures.
Several studies of the postural change of intraocular pressure in glaucoma have been carried out in the past several years. ${ }^{1-59-12}$ However, little has been written on ocular hypertension ${ }^{10}$ and low tension glaucoma. ${ }^{12}$ This paper was designed to confirm earlier reports regarding postural change of intraocular pressure in ocular hypertension and low tension glaucoma, and to investigate any possible relationship between blood pressure and intraocular pressure in these groups of patients.

\section{Subjects and methods}

The patients with ocular hypertension and with low tension glaucoma were selected after an observation term of one year from those attending the Glaucoma Clinic of the Department of Ophthalmology, Yamanashi Medical College, from April 1988 to December 1990. Ocular hypertension was defined as an intraocular pressure over $21 \mathrm{~mm} \mathrm{Hg}$ in eyes with normal visual fields, normal angles, and discs without glaucomatous cupping. Low tension glaucoma was defined as an intraocular pressure equal to or under $21 \mathrm{~mm} \mathrm{Hg}$ in eyes with glaucomatous changes in the visual fields and optic discs. No patients received any medication prior to or during the examination period.

Normal controls included normal volunteers and patients selected from the general clinics. These patients had either incipient cataract or refractive error only, and no other systemic abnormality. None of the controls was having any medication that is known to influence intraocular pressures.

An Alcon Pneumatonograph (Alcon Laboratories, Fort Worth, Texas) was used to measure the intraocular pressure in both the sitting and supine positions. Prior to use, the pneumatonograph was tested and calibrated against a Silastic membrane and hydrostatic pressure before every reading. In order to confirm the stability of intraocular pressure measurements calibrations were carried out with the pneumatonograph tip in both the horizontal and vertical positions. Briefly, at a preset pressure measurements were made with the pneumatonograph tip in the horizontal position. Thereafter, while the same pressure setting was maintained in the manometer, the pneumatonograph tip was shifted to the vertical position, and 10 consecutive measurements were made. Calibrations were made at pressure increments of $5 \mathrm{~mm} \mathrm{Hg}$, starting with an initial pressure of $5 \mathrm{~mm} \mathrm{Hg}$, up to $40 \mathrm{~mm} \mathrm{Hg}$.

For the actual measurements each subject was asked to sit comfortably at the edge of an examining table in a quiet room for 10 minutes. A topical anaesthetic was instilled into both eyes, 
Figure 1 Correlation between intraocular pressure readings with the pneumatonograph when the tip is in the horizontal position (horizontal axis) and in the vertical position (vertical axis). Correlation coefficient is 0.99 .

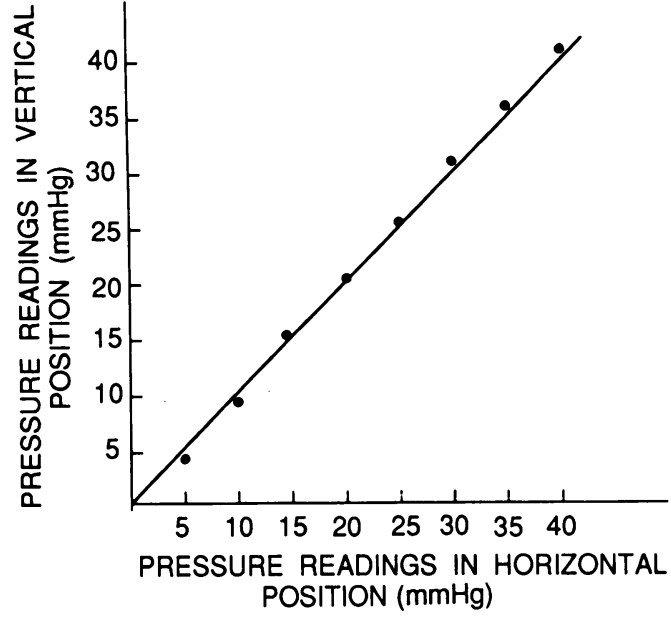

and the intraocular pressure of one eye, chosen at random, was measured while the patient was in a sitting position. Immediately after the intraocular pressure measurement the blood pressure was measured by means of a mercury sphygmomanometer. We made measurements from the left arm, making sure that the patient's arm was relaxed and that the sphygmomanometer was adjusted to a position approximating the level of the heart. Subsequently, the patient was asked to lie down and intraocular and blood pressure measurements were made in a similar manner. The intraocular pressure was measured in the same eye in which it was measured before. The patient was asked to remain in the supine position for 30 minutes, after which the intraocular and blood pressures were again measured. Finally, the patient was asked to sit up and the final measurements done. All measurements were taken by the same person (SY) in the morning, between 0900 and 1100 . Three readings were taken and the mean used for the study.

The Student's $t$ test for paired data was used for statistical analysis.

Table 1 Postural change of intraocular pressure

\begin{tabular}{|c|c|c|c|c|c|c|}
\hline & \multicolumn{2}{|c|}{$\begin{array}{l}\text { Normal } \\
\text { control } \\
(m m \mathrm{Hg})\end{array}$} & \multicolumn{2}{|c|}{$\begin{array}{l}\text { Low tension } \\
\text { glaucoma } \\
\text { (mm } \mathrm{Hg})\end{array}$} & \multicolumn{2}{|c|}{$\begin{array}{l}\text { Ocular } \\
\text { hypertension } \\
(\mathrm{mm} \mathrm{Hg})\end{array}$} \\
\hline & Mean & $(S D)$ & Mean & $(S D)$ & Mean & $(S D)$ \\
\hline $\begin{array}{l}\text { Sitting }(0) \\
\text { Supine }(0) \\
\text { Supine }(30) \\
\text { Sitting }(30)\end{array}$ & $\begin{array}{l}17 \cdot 5 \\
21 \cdot 9 \\
21 \cdot 9 \\
16 \cdot 7\end{array}$ & $\begin{array}{l}(3 \cdot 0) \\
\left(3 \cdot 6^{\star}\right) \\
(2 \cdot 9) \\
(2 \cdot 8)\end{array}$ & $\begin{array}{l}18 \cdot 4 \\
22 \cdot 5 \\
22 \cdot 6 \\
18 \cdot 2\end{array}$ & $\begin{array}{l}(2 \cdot 3) \\
\left(3 \cdot 2^{\star}\right) \\
(2 \cdot 8) \\
(2 \cdot 6)\end{array}$ & $\begin{array}{l}22 \cdot 5 \\
26 \cdot 5 \\
28 \cdot 1 \\
22 \cdot 3\end{array}$ & $\begin{array}{l}(3 \cdot 5) \\
\left(3 \cdot 5^{\star}\right) \\
(4 \cdot 2 \dagger) \\
(3 \cdot 2)\end{array}$ \\
\hline
\end{tabular}

Table 2 Postural change of systolic blood pressure

\begin{tabular}{|c|c|c|c|c|c|c|}
\hline & \multicolumn{2}{|c|}{$\begin{array}{l}\text { Normal } \\
\text { control } \\
(\mathrm{mm} \mathrm{Hg})\end{array}$} & \multicolumn{2}{|c|}{$\begin{array}{l}\text { Low tension } \\
\text { glaucoma } \\
(\mathrm{mm} \mathrm{Hg})\end{array}$} & \multicolumn{2}{|c|}{$\begin{array}{l}\text { Ocular } \\
\text { hypertension } \\
\text { (mm Hg) }\end{array}$} \\
\hline & Mean & $(S D)$ & Mean & $(S D)$ & Mean & $(S D)$ \\
\hline $\begin{array}{l}\text { Sitting (0) } \\
\text { Supine (0) } \\
\text { Supine (30) } \\
\text { Sitting (30) }\end{array}$ & $\begin{array}{l}140 \cdot 0 \\
137 \cdot 6 \\
135 \cdot 2 \\
136 \cdot 2\end{array}$ & $\begin{array}{l}(21 \cdot 4) \\
(19 \cdot 5) \\
(20 \cdot 7) \\
(22.9)\end{array}$ & $\begin{array}{l}140 \cdot 5 \\
142.5 \\
141 \cdot 5 \\
139 \cdot 5\end{array}$ & $\begin{array}{l}(27 \cdot 7) \\
(30 \cdot 7) \\
(27 \cdot 0) \\
(28 \cdot 8)\end{array}$ & $\begin{array}{l}132 \cdot 8 \\
135 \cdot 0 \\
126 \cdot 1 \\
126 \cdot 9\end{array}$ & $\begin{array}{l}(15 \cdot 0) \\
(14 \cdot 3) \\
\left(11 \cdot 1^{\star}\right) \\
(11 \cdot 9)\end{array}$ \\
\hline
\end{tabular}

$\star \mathrm{p}<0.003$ in comparison with baseline sitting blood pressure. $\mathrm{p}<0.001$ incomparison withinitialblood pressurein supine position.

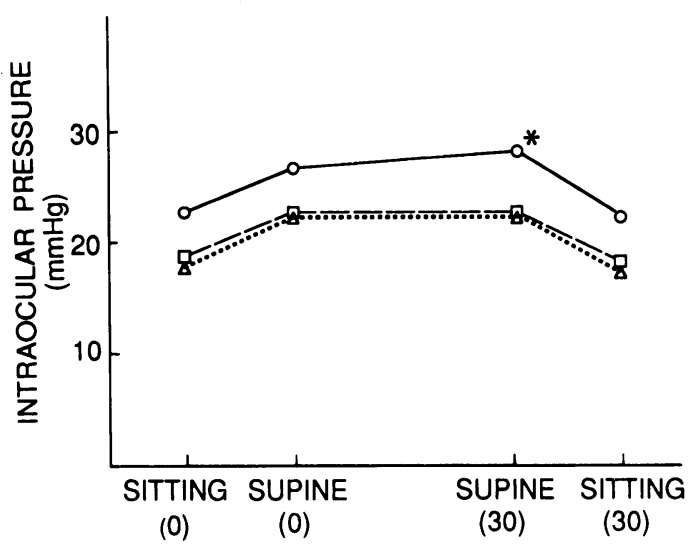

Figure 2 Mean intraocular pressure variations in normal control eyes (triangles and dotted line), low-tension glaucoma eyes (squares and dashed line), and ocular hypertension eyes (circles and solid line). Asterisk indicates a significant increase in intraocular pressure in eyes with ocular hypertension (see text).

\section{Results}

The results of our calibration measurements showed that pressure readings with the pneumatonograph tip in the vertical position correlated well with readings when the pneumatonograph tip was in the horizontal position. The correlation coefficient was calculated to be 0.99 (Fig 1).

The clinical tests were carried out on a total of 16 eyes with ocular hypertension (mean age (SD) $49 \cdot 4(11 \cdot 4)$ yr, 23 eyes with low-tension glaucoma $(62 \cdot 3(11 \cdot 1) \mathrm{yr})$, and 18 normal control eyes $(56 \cdot 5$ $(18 \cdot 8) \mathrm{yr})$. The results are illustrated in Tables 1 and 2 and Fig 2.

The intraocular pressure increased in all subjects on assuming the supine position (Table 1 and Fig 2). There was an average rise (with SD) of $4 \cdot 4(2 \cdot 0) \mathrm{mm} \mathrm{Hg}$ in normal controls, $4 \cdot 0(2 \cdot 0)$ $\mathrm{mm} \mathrm{Hg}$ in eyes with ocular hypertension, and $4 \cdot 1$ $(1.8) \mathrm{mm} \mathrm{Hg}$ in eyes with low-tension glaucoma. The resulting intraocular pressures were significantly different in comparison with baseline readings $(p<0.001)$.

Thereafter the pattern of intraocular pressure change associated with the sustained supine position was different in the three groups. After 30 minutes in the supine position the intraocular pressure in the control and low-tension glaucoma groups showed minimal, non-significant changes -0.05 (SD 1.97) $\mathrm{mm} \mathrm{Hg}$ and $0.07(1.48) \mathrm{mm} \mathrm{Hg}$, respectively. On the other hand the ocular hypertension group showed a further rise of intraocular pressure of $1 \cdot 6(2 \cdot 8) \mathrm{mm} \mathrm{Hg}$ (Table 1 and Fig 2). The resulting increased intraocular pressure in the ocular hypertension group was significantly different from both the baseline intraocular pressure $(p<0.001)$ and the initial lying intraocular pressure $(p=0.004)$. It was likewise significantly different from the intraocular pressure values of either the control or low-tension glaucoma groups $(\mathrm{p}<0.001)$.

The postural changes of systolic blood pressure were more variable (Table 2 ). In the normal controls the blood pressure decreased by 1.9 (SD 10.7) $\mathrm{mm} \mathrm{Hg}$ on lying down. After the controls remained supine for 30 minutes it further declined by $2.4(10.3) \mathrm{mm} \mathrm{Hg}$. These changes were all non-significant.

Systolic pressures in the low-tension glaucoma group registered an initial increase of 1.7 (SD 
$5 \cdot 2) \mathrm{mm} \mathrm{Hg}$ on lying down. After 30 minutes in the supine position the systolic pressure decreased by $1 \cdot 0(5 \cdot 2) \mathrm{mm} \mathrm{Hg}$. All changes were likewise non-significant in comparison with the baseline value or with each other.

As in the low-tension glaucoma group, systolic pressures in patients with ocular hypertension showed a slight rise of $2 \cdot 0$ (SD $4 \cdot 2) \mathrm{mm} \mathrm{Hg}$ on lying down. However after the patients remained supine for 30 minutes, the systolic pressures dropped by $9.5(6.4) \mathrm{mm} \mathrm{Hg}$. The resulting blood pressure values were significantly different from both the baseline sitting systolic pressure $(p=0.003)$ and the initial systolic pressure taken in the supine position $(\mathrm{p}<0 \cdot 001)$.

When the patients resumed the sitting position, both intraocular and systolic blood pressures returned nearly to baseline values.

\section{Discussion}

Intraocular pressures rose by approximately 4 $\mathrm{mm} \mathrm{Hg}$ in all the groups tested. Although our results confirm earlier findings of an increase in intraocular pressure with postural change, the magnitude of the rise differs slightly from those of previous reports. ${ }^{1-69-12}$ The rise among patients with low-tension glaucoma is more easily compared, since our study showed a much lower increment than in a previous report. ${ }^{12}$ The rise among ocular patients with hypertension is more difficult to comment on. Leonard and coworkers ${ }^{10}$ reported a rise of $0-9 \mathrm{~mm} \mathrm{Hg}$. While they found that $85 \%$ of eyes with ocular hypertension registered increases of $0-3 \mathrm{~mm} \mathrm{Hg}$, and only $15 \%$ showed $5-9 \mathrm{~mm} \mathrm{Hg}$, they failed to give a mean figure. We can only say therefore that our findings fall within the range cited.

We believe that the quantitative change in intraocular pressure is not as significant as the rise itself, since the figures reported in literature are very variable. A review shows that, in general, intraocular pressure rises from 0.3 to $6.0 \mathrm{~mm} \mathrm{Hg}$ when changing from a sitting to a supine position..$^{1-69-12}$ Our results are likewise well within this range.

The fact that the magnitude of the rise in intraocular pressure in the supine position was almost identical in all the three groups is interesting. While a little surprising, we believe that they are certainly not artefactual for a number of reasons. Firstly, interobserver bias was eliminated by having only one of us do the intraocular pressure measurements all the time. This further assured a constant technique. Secondly, the examination was performed at specific times of day in order to neutralise diurnal variation. Finally, the pneumatonograph, though already a well accepted method for taking sitting and supine intraocular pressures, ${ }^{13+1112}$ was further calibrated in both the horizontal and vertical positions and gave an excellent correlation coefficient.

The similarity of the intraocular pressure increments between the study groups precludes the possibility of using postural change of intraocular presssure as a diagnostic tool in the diagnosis of glaucoma. It also casts doubt on any possible pathogenetic role that the postural change of intraocular pressure itself might have in glaucomatous damage to the optic nerve head. The predictive value of such postural change is even more controversial. An earlier report ${ }^{12}$ states that patients with low-tension glaucoma showed a higher postural change than did normal people or patients with chronic open angle glaucoma, suggesting a possible predictive value for it. Our present results do not confirm this. The small number of subjects in the previous study may be a factor for this difference.

There has been speculation on the mechanism of postural intraocular pressure rise. Leonard and coworkers ${ }^{10}$ proposed that the immediate rise in intraocular pressure on lying down may be due to a sudden increase in uveal blood flow, while the sustained rise may be due to increased aqueous production or increased outflow resistance. Krieglstein and coworkers ${ }^{3}$ speculated that intraocular pressure rise is correlated with changes in episcleral venous pressure and ophthalmic arterial pressure. However, with our present results we tend to agree with the observation that the mechanism for the immediate as well as the persistent rise in intraocular pressure is a complex combination of factors. ${ }^{9}$ Fundamentally, therefore, the mechanism by which intraocular pressure increases in the supine position is still largely unknown.

The pattern of intraocular pressure change after 30 minutes in the supine position is more interesting. Among the three groups only the ocular hypertension group showed a continuing and significant rise in intraocular pressure after remaining supine. A similar response has been reported earlier by Williams and coworkers,? though this was demonstrated in patients with systemic hypertension. Thus there might be more things in common between systemic and ocular hypertension, especially if one considers the Framingham study demonstrating an association between ocular hypertension and systemic blood pressure. ${ }^{13}$ This will be discussed in more detail later.

The relationship of blood pressure to intraocular pressure has been extensively studied. ${ }^{7+17}$ At first glance our data do not seem to show any correlation between blood pressure and intraocular pressure, but close scrutiny reveals interesting patterns. The normal response to a postural change in our series is an initial decrease in blood pressure, followed by a further decrease while the patient is maintained in the supine position, then a rapid increase to baseline values on regaining the sitting position. On the contrary, the low-tension glaucoma group showed an initial increase, followed by a gradual decrease during the 30-minute period the patient was left lying, and a further decrease to baseline on sitting up. The response of the ocular hypertension group was the most interesting in the sense that it seems to be a mixture of the two responses. The initial response was an increase, followed by a decrease, and finally an increase towards baseline.

The initial response of the ocular hypertension group seems to parallel that of the low-tension glaucoma group. Thereafter the response closely parallels that of the normal control group. The dramatic decline of blood pressure might therefore be a delayed compensatory mechanism that 
would equilibrate and normalise haemodynamic as well as other unknown forces in order to approximate to the normal response. Since a sustained increase in intraocular pressure can have deleterious effects on visual function, ${ }^{18}$ the question whether the response seen in the ocular hypertension group is responsible for maintaining the integrity of the optic nerve head despite high intraocular pressures deserves some thought.

The unusual responses of the ocular hypertension group deserves some discussion, particularly in the light of its similarity to the response of systemic hypertensive patients. Since systemic hypertension is substantially an autonomic disorder, the question of whether ocular hypertension is also an autonomic disorder should be considered.

After noting unilateral intraocular pressure rises in some ocular hypertension patients Leonard and coworkers ${ }^{10}$ explained their observations on the basis of a local vasomotor dysfunction and speculated that the mechanism for intraocular pressure control may be located within the eye itself. They further cited Brazier's study demonstrating a change in intraocular pressure control in patients with Horner's syndrome after cervical sympathectomy. In so doing, the role of the autonomic system is introduced. The fact that intraocular pressure can be controlled with topical $\beta$ blockers further suggests that local adrenergic receptors play a part in intraocular pressure regulation. In a series of studies Clark and Mapstone have demonstrated that an autonomic defect indeed exists among ocular hypertension patients, not only locally within the eye ${ }^{1920}$ but also systemically. ${ }^{21}$ They even proposed that raised intraocular pressure may actually be a manifestation of a systemic disease.

A question arises whether low-tension glaucoma patients also have some autonomic dysfunction. This is highly probable considering the responses shown in this series. The degree of autonomic derangement might even be much more than ocular hypertension patients so as to blunt any capacity to 'recover' and approximate to the response of the normal population, resulting therefore in glaucomatous damage. Experiments are now under way in our clinics to investigate this hypothesis.

1 Jain MR, Marmion VJ. Rapid pneumatic and Mackay-Marg applanation tonometry to evaluate the postural effect on intraocular pressure. Brf Ophthalmol 1976; 60: 687-93.

2 Galin MA, McIvor JW, Brock Magruden G. Influence of position on intraocular pressure. Am $\mathcal{F}$ Ophthalmol 1963; 55: $720-3$.

3 Krieglstein GK, Waller WK, Leydhecker W. The vascular basis of the positional influence on the intraocular pressure. Graefes Arch Clin Exp Ophthalmol 1978; 206: 99-106.

4 Wüthrich UW. Postural change and intraocular pressure in glaucomatous eyes. Brf Ophthalmol 1976; 60: 111-4.

5 Weber AK, Price J. Pressure differential of intraocular pressure measured between supine and sitting position. Ann Ophthalmol 1981; 13: 323-6.

6 Trew DR, Smith SE. Postural studies in pulsatile ocular blood flow: I. Ocular hypertension and normotension. $\mathrm{Br} F$ Ophthalmol 1991; 75: 66-70.

7 Williams BI, Peart WS, Letley E. Abnormal intraocular pressure control in systemic hypertension and diabetes mellitus. BrF Ophthalmol 1980; 64: 845-51.

8 Radius RL. Anatomy and pathophysiology of the retina and optic nerve. In: Ritch R, Shields MB, Krupin T, eds. The glaucomas. St Louis: Mosby, 1989: 123-4.

9 Anderson DR, Grant WM. The influence of position on intraocular pressure. Invest Ophthalmol Vis Sci 1973; 12: 204-12.

10 Leonard TJK, Kerr Muir MG, Kirkby GR, Hitchings RA. Ocular hypertension and posture. $\mathrm{Br} \mathcal{F}$ Ophthalmol 1983; 67: $362-6$.

11 Shibata T, Kondo K, Mishima H. The effects of body position on intraocular pressure in normal and glaucomatous eyes. Nippon Ganka Gakkai Zasshi 1986; 89: 696-701.

12 Tsukahara S, Sasaki T. Postural change of IOP in normal persons and in patients with primary open-angle glaucoma and low-tension glaucoma. Br F Ophthalmol 1984; 68: 38992.

13 Stone RA. Systemic diseases associated with elevated intraocular pressure and secondary glaucoma. In: Ritch $\mathbf{R}$, Shields MB, Krupin T, eds. The glaucomas. St Louis: Mosby, 1989: 1151.

14 Geijer C, Bill A. Effects of raised intraocular pressure on retinal, prelaminar, laminar, and retrolaminar optic nerve blood flow in monkeys. Invest Ophthalmol Vis Sci 1079; 18: 1030-42.

15 Bartels SP. Aqueous humour formation. In: Ritch R, Shields MB, Krupin T, eds. The glaucomas. St Louis: Mosby, 1989: 200.

16 Leighton DA, Phillips CI. Systemic blood pressure in openglaucoma, low tension glaucoma, and the normal eye. $\mathrm{BrF}$ Ophthalmol 1972; 56: 447-53.

17 Werner EB. Low-tension glaucoma. In: Ritch R, Shields MB Krupin T, eds. The glaucomas. St Louis: Mosby, 1989; 804.

18 Linder BJ, Trick GL, Wolf ML. Altering body position affects intraocular pressure and visual function. Invest Ophthalmol Vis Sci 1988; 29: 1492-7.

19 Clark CV, Mapstone R. Anterior segment autonomic dysfunction in ocular hypertension. Doc Ophthalmol 1986; 64: 201-7.

20 Clark CV , Mapstone R. Parasympathetic denervation hypersensitivity of the iris in ocular hypertension. Invest Ophthalmol Vis Sci 1987; 28: 1732-5.

21 Clark CV, Mapstone R. Autonomic neuropathy in ocular hypertension. Lancet 1985; ii: 185-7. 